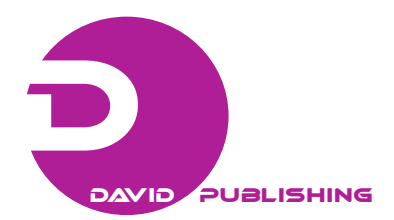

\title{
Strength Development of Cement-Slag Mortars
}

\author{
Fathollah Sajedi \\ Department of Civil Engineering, Islamic Azad University- Ahvaz Branch, Iran
}

\begin{abstract}
In this experimental work, three groups of cement-slag mortars namely OPC, OPC-slag, and slag mortars were made. All were cured in both water and air under room temperature. Strength development was studied up to 90 days. The mortars were prepared using $0 \%, 50 \%$, and $100 \%$ replacement with slag. The sensitivity for all groups was obtained against the curing regime with the highest being attributed to the slag mortars. The highest and lowest strengths at early ages were attributed to OPC and slag mortars when both were cured in water. The highest and lowest strengths were attributed to OPC-slag and slag mortars at later ages, respectively. The highest strengths for OPC-slag, OPC, and slag mortars were as $72.0,64.0$, and $21.5 \mathrm{MPa}$ at 90 days when the specimens cured in water, respectively. Strength loss was observed for all groups at later ages when cured in air under room temperature. The maximum and minimum, of about $8.0 \%$ and $1.3 \%$, occurred at 56 and 90 days for slag and OPC-slag mortars, respectively.
\end{abstract}

Key words: OPC-slag mortars, slag mortars, OPC mortars, compressive strength, strength development, strength loss.

\section{Introduction}

Generally, cement-slag mortars can be classified into three groups as: ordinary Portland cement mortars (OMs), slag mortars (SMs), and ordinary Portland cement-slag mortars (OSMs) [1].

\subsection{Ordinary Portland Cement Mortars}

This type of mortars is the most famous mortars in building activities. It has been used for many years ago. Nowadays, it is preferred that some of new products in industry are replaced with a part of cement in OPC mortars, in due to economic and environmental benefits. The mortars will be obtained high early and ultimate strengths whenever cured in the water. Because of high rate of hydration heat of cement, the rate of hydration heat in OPC mortars is faster than that of OPC-slag mortars and slag mortars, especially at early ages. Based on the results obtained in the study, it was observed that before 3 days the strength of OPC mortars is much more than that of OPC-slag mortars and slag mortars and moreover, the rate of strength growth is also faster. This reality is proven for both

Corresponding author: Fathollah Sajedi, $\mathrm{PhD}$, research fields: activation methods of cement-slag mortars and concretes. E-mail: f_sajedi@yahoo.com. curing regimes water and room temperature. It is noted that the economic and constructional expenses of OPC mortars are much more than those of OPC-slag mortars and slag mortars. Likewise, it is generally accepted that durability of OPC mortars is less than that of OPC-slag mortars and slag mortars. In addition, OPC mortars have lower resistance against sulfate attack and chloride ingress compared to OPC-slag mortars and slag mortars.

\subsection{Slag Mortars}

Ground granulated blast furnace slag is classified as a latently hydraulic material which can exhibit a hydraulic activity only with the presence of appropriate activators. It is widely accepted that blast furnace slag concrete produces a low heat of hydration, and have a superior durability against aggressive environment. The superior durability of blast furnace slag concrete against chemical attacks allows this mineral admixture a suitable binder for the concrete exposed to chloride, acid and sulfate attacks. However, it has been reported that concretes bearing high amount of blast furnace slag have a poor resistance against carbonation. The carbonation on blast furnace slag mixture transforms the C-S-H gel to porous silicate hydrates, and the strength reduction of the matrix might be expected. 
Consequently, the carbonated blast furnace slag concrete is vulnerable to scaling under the combined load of freezing-thawing and de-icing salt. Due to concrete surface disintegration, also other chemical attacks on the structure have more chance, which can result in a dramatic decrease in durability [2].

Extensive investigations on alternative inorganic materials which could replace conventional cement have been recently conducted to reduce greenhouse gas emissions from cement kilns. As a result, alkali-activated ground granulated blast-furnace slag cement or fly ash-based polymer cement have been investigated in many fields to act as binder to produce cement less mortar or concrete. Based on extensive literature review, Wang et al. [3] concluded that alkali-activated cement using ggbfs should be considered as an effective binder to produce better quality concrete than ordinary Portland cement concrete. The knowledge of the mechanism of alkali activation process is considerably advanced since the alkali-activated ggbfs cement and concrete were invented in the US in 1957 by Glukhovsky [4]. However, there are still many challenges to be tackled. Wang et al. [5] pointed out that sodium silicate solutions of modulus in the range of 1-1.5 is the best formulation for good strength development of alkali-activated ggbfs concrete. On the other hand, based on tests of alkali-activated low-calcium fly ash concrete, Hardjito et al. [6] concluded that a combination of sodium hydroxide and sodium silicate solutions can be a good application for activator and higher concentration of sodium hydroxide solution and curing temperature enable the concrete compressive strength to be higher [7].

The compressive strength of air-cured mortars activated only by the calcium hydroxide reduced after 56 days by an average of $15 \%$ of their own 28-day strength, whereas that of alkali-activated mortars in which barium hydroxide was added improved significantly at a long-term age. When the content of barium hydroxide was between $1 \%$ and $2.5 \%$, a higher long-term strength was obtained. As reported by Shi et al. [8], calcium hydroxide in the $\mathrm{Ca}(\mathrm{OH})_{2}$-activated ggbfs pastes is depleted rapidly for the first 3 days, and the reaction rate of calcium hydroxide significantly decreased after 14 days, which causes an unstable strength development at a long-term age. The addition of less than $2.5 \%$ barium hydroxide can stabilize the reactivity of $\mathrm{Ca}(\mathrm{OH})_{2}$-activated ggbfs pastes at a long-term age, and results in improving their long-term strength [9]. In this type of mortar which slag is only used, the both initial and ultimate strengths are very low. Based on the results of the study it was observed that this type of mortar has the lowest strengths among the mortars. The strengths obtained at 7 and 90 days for slag mortars were 11.1 and $21.4 \mathrm{MPa}$, respectively. A comparison of the results obtained with the same strengths of OPC-slag mortars and OPC mortars show that the strengths of slag mortars are lower than those of OPC-slag mortars and OPC mortars by about $77 \%$, $77 \%, 70 \%$, and $66 \%$, respectively. However, these mortars do not show a loss of strength when cured in water.

\subsection{Ordinary Portland Cement-Slag Mortar}

In this type of mortars the both cement and slag are used. The level of slag used is different and depends on the purpose of usage and construction. In due to the level of slag used is different, this type of mortars can be made with different properties. Many factors are affecting on the strength of the mortar such as the level of slag used, type of slag, glassy percentage of the slag, type of cement with its content, and the technique used to grind the binders. Additionally, it is generally accepted that the mortars have higher durability and ultimate strengths than that of OPC mortars. They also are more resistance against sulfate attacks and chloride ingress and have several benefits from economic and environmental viewpoints compared to slag mortars and OPC mortars. It is noted that some grades of the mortars such as OPC-slag mortars for $40 \%$ replacement with slag has strength loss at later ages, i.e., 
56 days and above [10]. It can be explained many factors affecting on the strength loss at later ages such as the level of slag used, the regime of curing, the nature and glassy content of slag, water-slag ratio, water-binder ratio, and the technique and type of grinder machine used to grind the binders.

\subsection{Strength Development}

High-slag-cements have low strength at early ages. The early strength of slag concrete is likely to be lower than ordinary Portland cement concrete, however at later ages to be higher as shown in Fig. 1. The initial hydration of slag is very slow because it depends upon the breakdown of the glass by the hydroxyl ions. Generally, the higher the slag contents the slower the development, but the higher the long-term gain (Wrainwright, 1986). The progressive release of alkalis by slag and together with the formation of calcium hydroxide by Portland cement results a continuous reaction of slag over a long period. However, the later rate of hydration is accelerated. A $50 \%$ slag replacement in the cementitious material is the highest medium-term strength but gives lower early strength than ordinary Portland cement (Dubovoy et al., 1986). Roy and Idorn, 1982 also suggested that the optimum slag content is about $50 \%$ from a strength point of view as shown in Fig. 2. Sivasundaram and Malhotra, 1992 reported that a remarkable strength development of $50 \%$ to $75 \%$ of slag with a total content of cementitious material between 300 and $420 \mathrm{~kg} / \mathrm{m}^{3}$. However Bagel, 1998 found that the replacement of $50 \%$ cement by slag caused significant reduction in the 90 days strength of mortar regarding to ordinary Portland cement mortar.

Based on the previous work [11] the use of slag in cement is known to cause decreased early age strength compared to that of Portland cement concrete. However, as shown in Fig. 3, the ultimate strength can increase with the addition of slag. The strength development of slag cement concrete is more sensitive to the curing temperature than Portland cement concrete. Low temperature can remarkably retard the strength gain and cause problems when the early age strength is important (Dubovoy et al., 1986). High fineness of slag cement increases the compressive strength, but the enhancement is much less prominent at early ages than that for Portland cement. As shown in Fig. 4, the compressive strength increases with increasing glass content in the slag as well, especially regarding to the later ages. However, slag with completely vitreous glass does not always lead to the

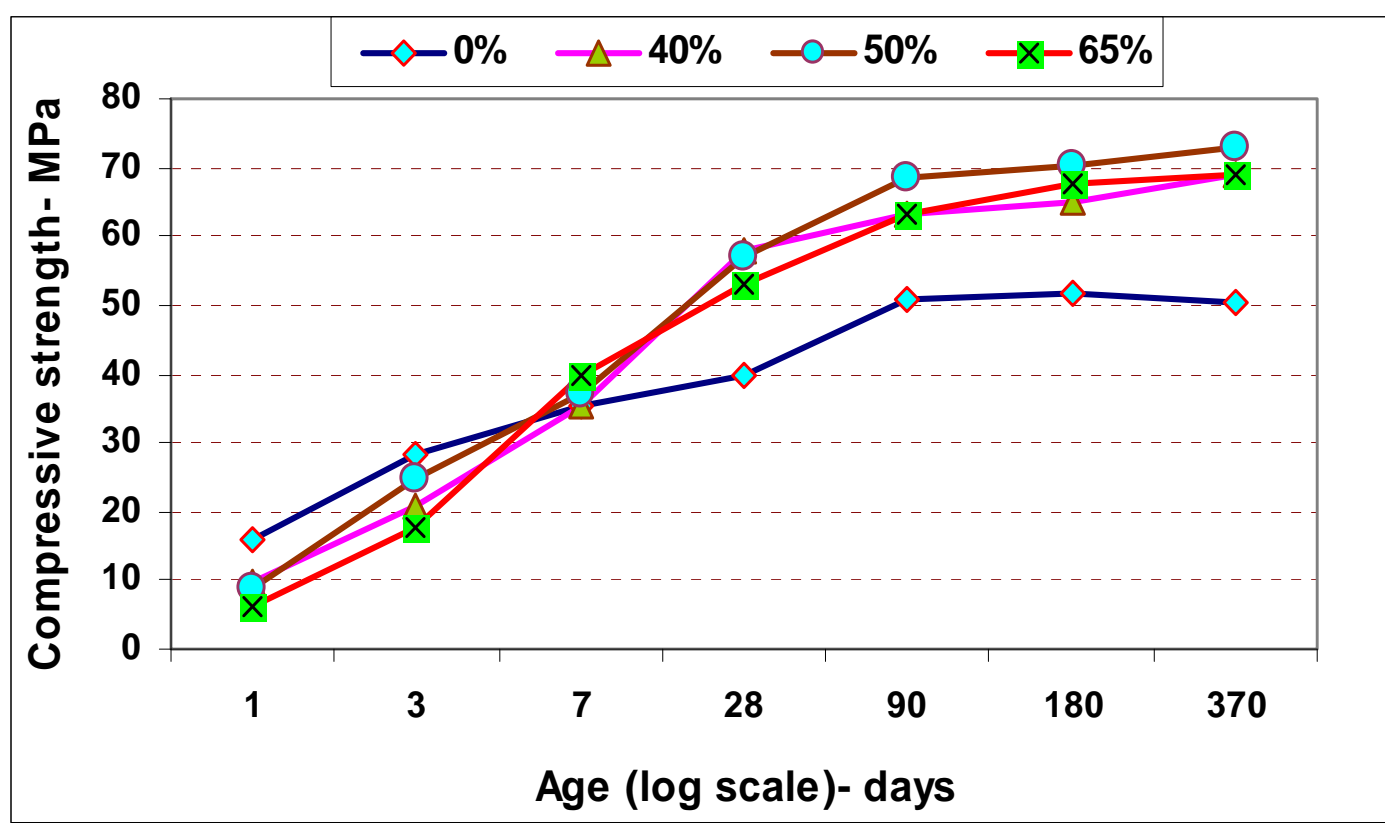

Fig. 1 Strength development for various slag contents (Hogan and Muesel, 1981). 


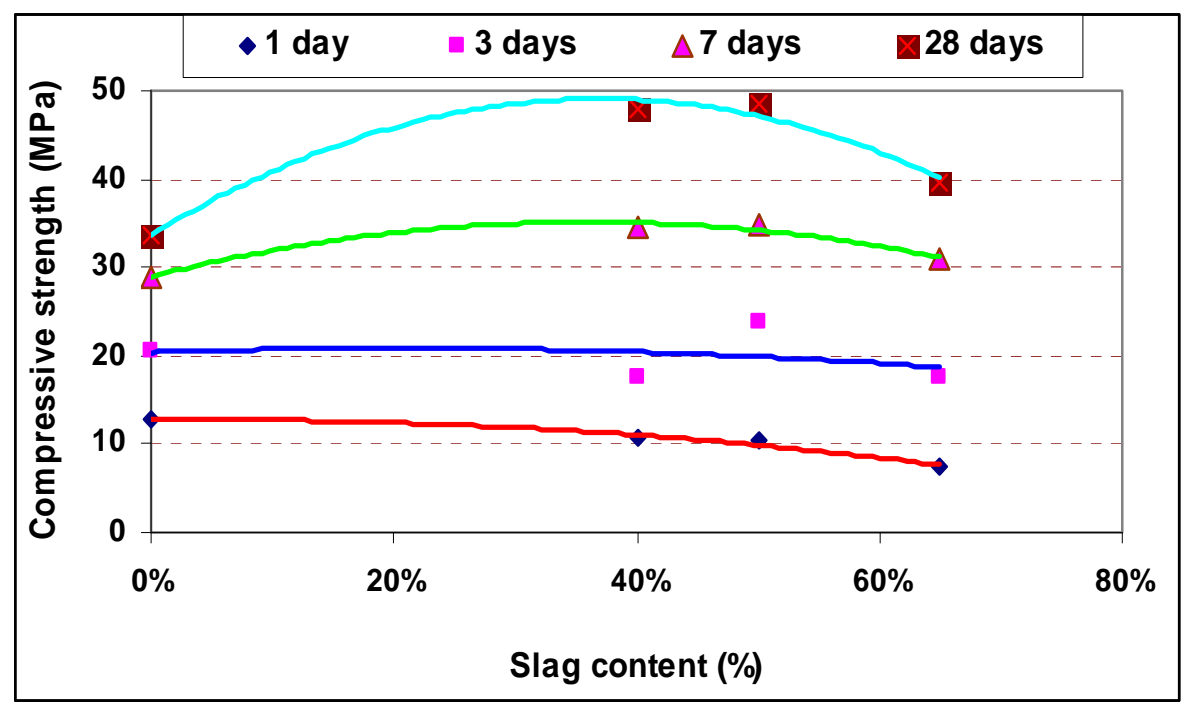

Fig. 2 Strength development for various slag contents (Roy and Idorn, 1982).

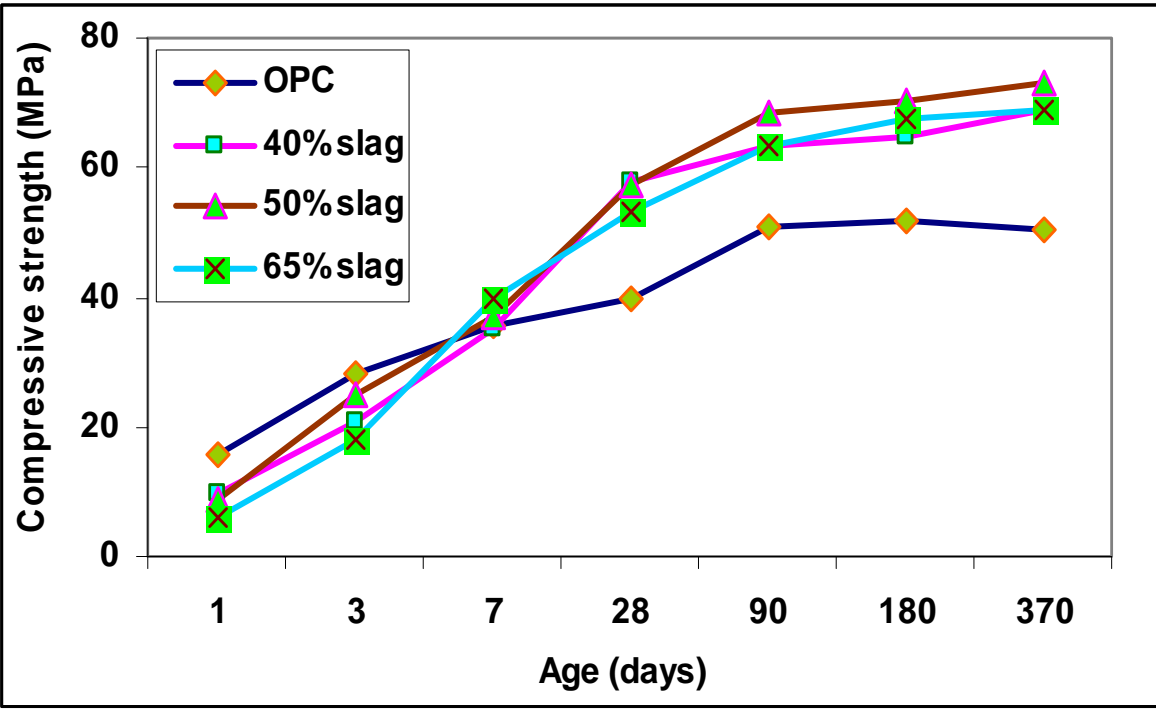

Fig. 3 Compressive strength development of mortar cube specimens containing various contents of slag (Dubovoy et al., 1986).

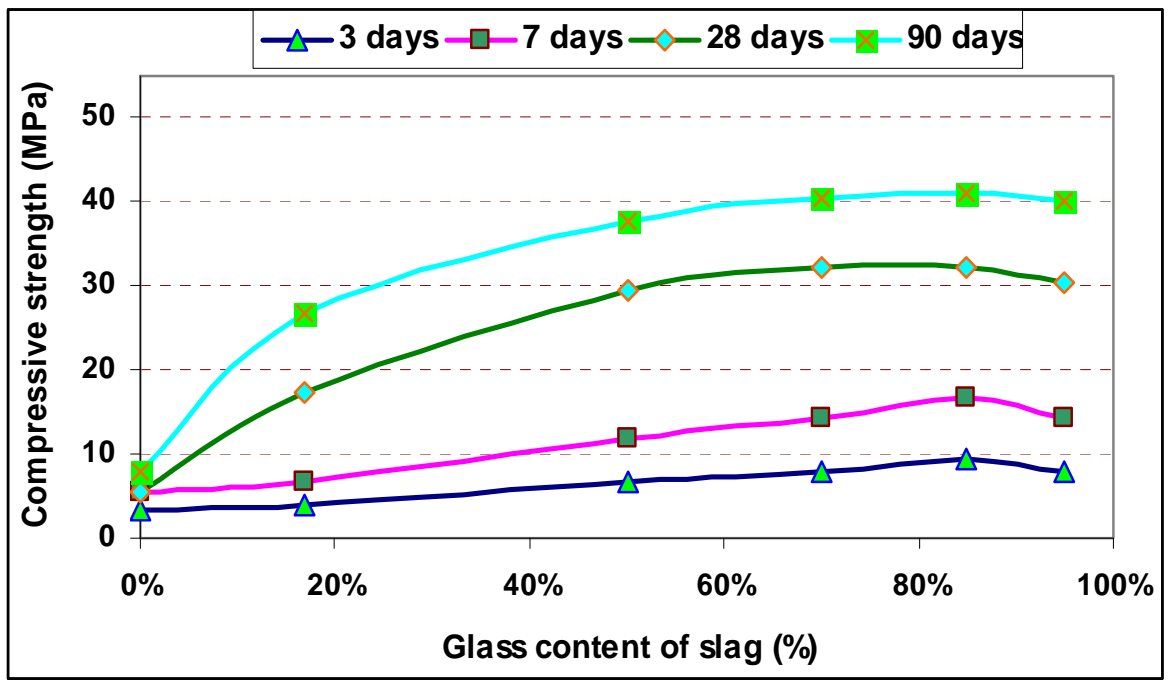

Fig. 4 Effects of glass content in slag on the compressive strength development of mortars (Frigione, 1986). 
highest strength. A low percentage of crystallization, i.e., $3 \%$ to $5 \%$ in mass, was found to be beneficial to the compressive strength development (Frigione, 1986).

Md. Moinul Islam et al., 2009 reported [13] that the development of compressive strength for cement slag mortar is not significant at the early age of curing. The gain in strength occurs at relatively rapid rate at later ages of curing. They claimed that mix proportion of slag with cement has a significant effect on strength development of slag mortar. They also noted that among mix proportions cement-slag ratios 85:15, $70: 30$, and 55:45, mortar mix with the ratio of $70: 30$ gives higher compressive strength for all water-binder ratios. Moreover, they observed that the rate of compressive strength deterioration of cement slag mortar mix 70:30 is lower than any other cement slag mortar for all water-binder ratios. In this type of mortar both cement and slag are used. The level of slag used is different and depends on the purpose of usage and construction. Based on the earlier part of the research done by the authors, in this study a $50 \%$ level was obtained as optimum [10]. When a 50\% level of replacement slag is used, it can achieve the highest strengths at later ages and, usually, after 7 days the strength of the mortar is greater than that of OPC mortars of the same age and proportion. In addition, it was determined that there is no strength loss at any age of OSM/50-wc. Because the level of slag used is different, this type of mortar can be made with different properties. Many factors affect the strength of the mortar such as the level of slag used, type of slag, glassy percentage of the slag, type of cement with its content, and the technique used for grinding of the binders. The results of the study have shown that there is no strength loss of OPC-slag mortars when the specimens are cured in water. Additionally, it is generally accepted that the mortars have higher durability and ultimate strengths than those of OPC mortars. They also have higher resistance against sulphate attack and chloride ingress, and have several advantages from economic and environmental viewpoints compared to the both slag mortars and OPC mortars. It is noted that some groups of OPC-slag mortars, such as OSM/40, have a strength loss at later ages, e.g., 56 days [10]. In this investigation, it was revealed that the strength loss of OSM/40 at 56 days compared to the strength at 28 days is about $11 \%$ [10]. This can be explained by many factors that affect the strength loss at later ages, namely the level of slag used, the regime of curing, the nature and glassy content of slag, water-slag ratio, and water-binder ratio.

The objective of this paper is to describe and compare the behavior of different types of OPC-slag mortars in curing regimes water and air under room temperature. Moreover, for all the three groups of mortars, the compressive strength loss is examined and the affected factors are studied. Finally, proper relationships are presented for the description of the strength development of OPC-slag mortars.

\section{Experimental Procedure}

\subsection{Properties of Materials}

The properties of materials used in the study are as follows:

\subsubsection{Cement}

The cement used in all the mixes was ordinary Portland cement (OPC). ASTM C109-99 [14] was used for the determination of the compressive strength of hydraulic cement mortars, using $50 \mathrm{~mm}$ sided cube specimens. The specific gravity of the cement used is about 3.14. Based on the particle size analysis tests, the specific surface area (SSA) for OPC was measured by Stephen Brunauer, Paul Hugh Emmett, and the Edward Teller (BET) method and determined to be $1893.9 \mathrm{~m}^{2} / \mathrm{kg}$. The chemical compositions of OPC used in this research were determined by the testing method "X-ray fluorescence spectrometry (XRF)". The results are given in Table 1.

\subsubsection{Slag}

The specific gravity of the ground granulated blast furnace slag (ggbfs) is approximately 2.87, with its 
bulk density varying in the range of $1180-1250 \mathrm{~kg} / \mathrm{m}^{3}$. The color of the slag is normally whitish (off-white). Based on the PSA tests, the SSA for slag has been determined at $3597.2 \mathrm{~m}^{2} / \mathrm{kg}$. It can be seen that $\mathrm{SSA}_{\text {slag }}=$ $1.90 * \mathrm{SSA}_{\mathrm{OPC}}$, which means that particles of slag are $90 \%$ finer than that of OPC. The compositions of slag are given in Table 1 . As with all cementing materials, the reactivity of the slag is determined by its SSA. Based on the definition of the slag activity index (SAI) in ASTM C989 [15], it can be seen that $\mathrm{SAI}=$ $(\mathrm{SP} / \mathrm{P}) * 100$, where; $\mathrm{SP}=$ average compressive strength of slag-reference cement mortar cubes; and $\mathrm{P}=$ average compressive strength of the reference cement mortar cubes. Both compressive strengths are in MPa. Based on this definition, the slag used in the tests is classified as Grade 120. A result calculation is shown at the bottom of Table 1 .

\subsubsection{Aggregate}

The fine aggregate used in all the mixes is graded silica sand with a specific gravity, fineness modulus (FM) and water absorption (BS812: Clause 21) of 2.68, 3.88 and $0.93 \%$, respectively. The maximum size of aggregate is $4.75 \mathrm{~mm}$. The grain size distribution for the silica sand used in the mixes is: $12 \%$ mesh $50 / 100$, $18 \%$ mesh $30 / 60,30 \%$ mesh $16 / 30,20 \%$ mesh $8 / 16$ and $20 \%$ mesh $4 / 6$. The grain size distribution diagram and data analysis for the graded silica sand are shown in Fig. 5 and Table 2, respectively.

Table 1 Compositions of cementitious materials used in the study ( $\%$ by mass).

\begin{tabular}{|c|c|c|c|c|c|c|c|c|c|c|}
\hline \multicolumn{11}{|c|}{ For OPC } \\
\hline $\mathrm{SiO}_{2}$ & $\mathrm{Al}_{2} \mathrm{O}_{3}$ & $\mathrm{MgO}$ & $\mathrm{Fe}_{2} \mathrm{O}_{3}$ & $\mathrm{CaO}$ & $\mathrm{MnO}$ & $\mathrm{K}_{2} \mathrm{O}$ & $\mathrm{TiO}_{2}$ & $\mathrm{SO}_{3}$ & $\mathrm{CO}_{2}$ & LOI \\
\hline 18.47 & 4.27 & 2.08 & 2.06 & 64.09 & 0.05 & 0.28 & 0.11 & 4.25 & 4.20 & 1.53 \\
\hline \multicolumn{11}{|c|}{ For Slag } \\
\hline $\mathrm{SiO}_{2}$ & $\mathrm{Al}_{2} \mathrm{O}_{3}$ & $\mathrm{MgO}$ & $\mathrm{Fe}_{2} \mathrm{O}_{3}$ & $\mathrm{CaO}$ & $\mathrm{MnO}$ & $\mathrm{K}_{2} \mathrm{O}$ & $\mathrm{TiO}_{2}$ & $\mathrm{SO}_{3}$ & $\mathrm{CO}_{2}$ & $\mathrm{Na}_{2} \mathrm{O}$ \\
\hline 31.21 & 12.96 & 4.27 & 0.87 & 41.47 & 0.21 & 0.31 & 0.49 & 2.04 & 6.00 & 0.11 \\
\hline \multicolumn{11}{|c|}{ For 7 days; $\mathrm{SAI}=47.57 / 47.76=1.00>0.95 ; \quad$ For 28 days; $\mathrm{SAI}=62.83 / 50.26=1.25>1.15$} \\
\hline \multicolumn{11}{|c|}{$\begin{array}{l}K_{b} \text { (Basicity Index) for slag }=(41.47+4.27) /(31.21+12.96)=1.03>1.00 \text { then the slag is basic. } \\
\qquad 1.30 \leq \mathrm{CaO} / \mathrm{SiO}_{2}=\mathrm{C} / \mathrm{S}=1.33 \text { for } \mathrm{slag} \leq 1.40\end{array}$} \\
\hline
\end{tabular}

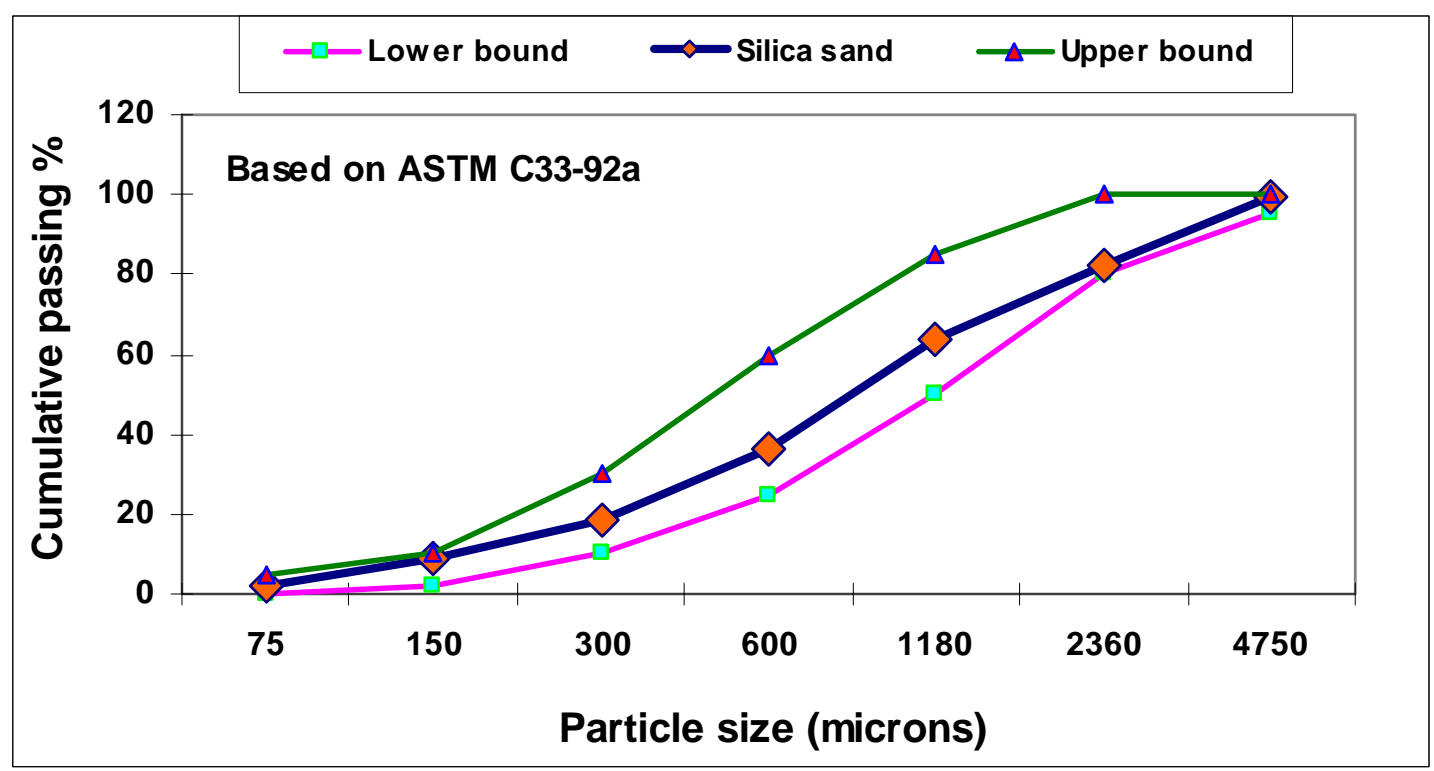

Fig. 5 Grain size distribution diagram for silica sand. 
Table 2 Particle size analysis for silica sand based on BS 822: Clause 11.

\begin{tabular}{|c|c|c|c|c|c|c|c|}
\hline $\begin{array}{l}\text { Sieve size } \\
(\mu \mathrm{m})\end{array}$ & $\begin{array}{c}\text { Sieve } \\
\text { NO }\end{array}$ & $\begin{array}{c}\mathrm{W}_{\mathrm{SS}^{+}} \\
\mathrm{W}_{\mathrm{S}}(\mathrm{g}) \\
\end{array}$ & $\begin{array}{l}\mathrm{W}_{\mathrm{S}} \\
(\mathrm{g}) \\
\end{array}$ & $\begin{array}{l}\mathrm{W}_{\mathrm{SS}} \\
(\mathrm{g})\end{array}$ & $\begin{array}{c}\text { Ret. } \\
\%\end{array}$ & $\begin{array}{c}\text { Cumul. Ret. } \\
\%\end{array}$ & $\begin{array}{c}\text { Cumul. pass. } \\
\%\end{array}$ \\
\hline 4750 & NO 4 & 409.9 & 408.3 & 1.6 & 0.32 & 0.32 & 99.68 \\
\hline 2360 & NO7 & 462.3 & 375.7 & 86.6 & 17.33 & 17.65 & 82.35 \\
\hline 1180 & NO14 & 437.2 & 343.0 & 94.2 & 18.85 & 36.5 & 63.50 \\
\hline 600 & $\mathrm{NO} 25$ & 450.7 & 316.2 & 134.5 & 26.92 & 63.42 & 36.58 \\
\hline 300 & NO52 & 379.1 & 288.7 & 90.4 & 18.09 & 81.51 & 18.49 \\
\hline 150 & NO100 & 322.1 & 274.8 & 47.3 & 9.47 & 90.98 & 9.02 \\
\hline 75 & NO200 & 309.9 & 275.2 & 34.7 & 6.94 & 97.92 & 2.08 \\
\hline pan & ---- & 250.8 & 240.4 & 10.4 & 2.08 & 100.00 & 0.00 \\
\hline Total & & & & 499.7 & ---- & 388.30 & \\
\hline
\end{tabular}

\subsubsection{Super Plasticizer}

In order to have appropriate consistency with low $\mathrm{w} / \mathrm{b}$ ratio, super plasticizer is used. The brand of super plasticizer used in this investigation is Rheobuild 1100. It is a chloride-free product. The specific gravity of the super plasticizer is approximately 1.195 , and is dark brown in color with a $\mathrm{pH}$ in the range of 6.0 to 9.0. The consumed amount of super plasticizer in the mortar depends on the levels of cement and replacement slag. It is compatible with all cements and admixtures meeting ASTM and UNI standards. Meet ASTM C-494 [18] Types A and F and also meet BS 5075 Part 1 and 3 . The basic components are synthetic polymers which allow mixing water to be reduced considered. The dosage of super plasticizer generally varies from 0.8 to 1.2 liter $/ 100 \mathrm{~kg}$ of cement. Other dosages may be recommended in special cases according to specific job conditions.

\subsubsection{Water (Mixing and Curing)}

The water used in making and curing concrete, mortar, and grout should be free from objectionable quantities of silt, organic matter, salts, and other impurities. In no case should mix water contain more than 3000 ppm soluble sulphate [19]. Combining water with a cementitious material forms a cement paste by the process of hydration. The cement paste glues the aggregate together, fills voids within it, and allows it to flow more freely. Less water in the cement paste will yield a stronger, more durable concrete; more water will give a freer-flowing concrete with a higher slump. Using impure water to make concrete can cause problems when setting or premature failure of the structure. Both the water used in all mixes and in moist curing of the specimens was potable water from the pipeline of the lab. It was assumed that the specific gravity of the used water is about $1 \mathrm{~g} / \mathrm{cm}^{3}$.

\subsection{Mix proportions and Curing}

Table 3 presents the mix proportions for different types of mortars. The water-binder and sand-binder ratios for all the mixes were 0.33 and 2.25 , respectively. Silica sand was used in the mixes. Initially, five grades of silica sands were mixed for 2 minutes, cement and replacement slag were then added to the mixture, followed by 3 to 4 minutes of mixing. Mixing water was then added to the mix and mixing was continued for 2 minutes, following which the required amount of super plasticizer was added. Mixing was continued for 2 minutes before the moulds were filled with fresh mortar in two layers. Each layer was compacted with ten impacts by a rod with $16 \mathrm{~mm}$ diameter. The specimens were demoulded 24 hours after casting and cured proportionally in water with $23 \pm 3^{\circ} \mathrm{C}$ or in air under room temperature $28 \pm 4^{\circ} \mathrm{C}$ and $65 \pm 20 \%$ relative humidity until the test day.

2.2.1 Testing procedures

(1) Workability Test 
In order to achieve an appropriate consistency for each mortar mix after casting, a flow table test was done. The flow values were within the range of 220 to $235 \mathrm{~mm}$. The test procedure includes casting; some mortar was put in the truncated brass cone in two layers. Each layer was compacted 10 times by a steel rod of 16 $\mathrm{mm}$ diameter, before the cone was lifted and the mortar collapsed on the flow table. Subsequently, both the table and mortar were jolted 15 times for a period of 60 s. Jolting the table enables the mortar to spread out and the maximum spread to the two edges of the table was then recorded. The average of both records was calculated as flow in $\mathrm{mm}$. The flow table tests were done according to ASTM C230/C230M- 08 [20]. The photograph for the mixer and flow table test is shown in Fig. 6.

(2) Compressive Strength Test

Three cubic specimens, with lengths of $50 \mathrm{~mm}$, were used for each age. Specimens produced from fresh mortar were demoulded after 24 hours, and then cured in air or in the water under room temperature before the samples were used for compressive strength tests. Compressive strength measurements were carried out using an ELE testing machine press with a capacity of $2000 \mathrm{kN}$, and a pacing rate of $0.5 \mathrm{kN} / \mathrm{s}$. Compressive strength tests were done according to BS 1881, Part $116,1983$.

Table 3 Mix proportions of all the three groups of mortars for the both curing regimes water and air under room temperature.

\begin{tabular}{|c|c|c|c|c|c|c|c|}
\hline No & Mix name & Curing regime & OPC $(\mathrm{g})$ & Slag $(\mathrm{g})$ & Water $(\mathrm{g})$ & Flow $(\mathrm{mm})$ & SP $(\mathrm{g})$ \\
\hline 1 & OM- ac & air & 1800 & 0.0 & 632.0 & 230 & 28 \\
\hline 2 & OSM/50- ac & air & 900 & 900 & 632.0 & 220 & 28 \\
\hline 3 & OM- wc & water & 1800 & 0.0 & 632.0 & 230 & 30 \\
\hline 4 & OSM/50- wc & water & 900 & 900 & 632.0 & 235 & 40 \\
\hline 5 & SM- ac & air & 0.0 & 1800 & 632.0 & 230 & 50 \\
\hline 6 & SM - Wc & water & 0.0 & 1800 & 632.0 & 225 & 45 \\
\hline
\end{tabular}

in all the mixes: water-binder ratio $=0.33$, sand-binder ratio $=2.25, \mathrm{wc}=$ water curing and $\mathrm{ac}=\mathrm{curing}$ in air under room temperature

Grain size distribution for silica sand used in the mixes is as: $12 \%$ mesh 50/100, 18\% mesh 30/60, 30\% mesh 16/30, $20 \%$ mesh $8 / 16$, and $20 \%$ mesh $4 / 6$

Notes: $\mathrm{OSM} / 50=\mathrm{OPC}$-slag mortars for $50 \%$ replacement with slag, $\mathrm{OM}=\mathrm{OPC}$ mortar, $\mathrm{SM}=$ slag mortar, $\mathrm{wc}=$ water curing, ac $=\mathrm{curing}$ in air under room temperature.
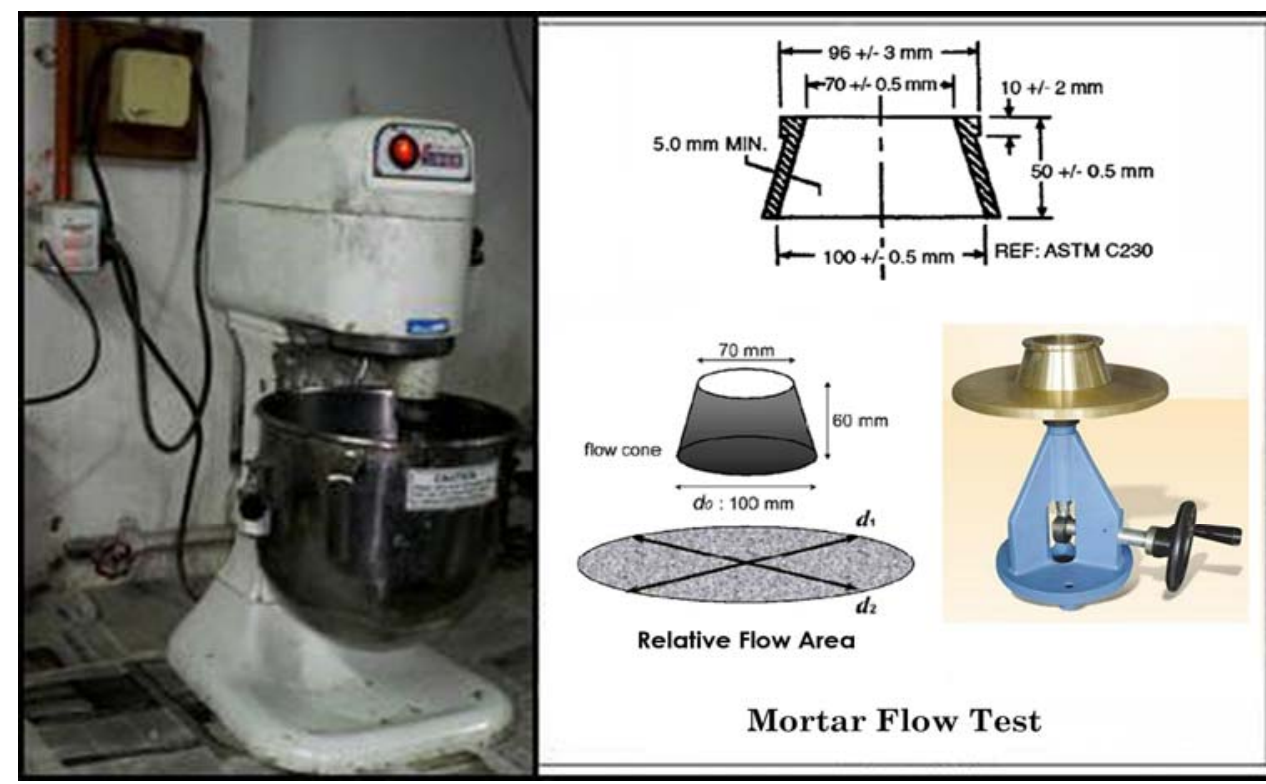

Mortar Flow Test

Fig. 6 Photograph for the mixer and flow table test. 


\section{Results and Discussion}

\subsection{Comparison of Curing Regimes}

Curing regimes and curing duration have crucial effects on the strength and other mechanical properties of mortars and concretes. Proper curing can protect against moisture loss from fresh concrete and can significantly affect the strength and other properties. The development of mortar properties such as strength depends on the hydration of cement. After placement, the only factors that influence cement hydration of a particular mortar are the availability of moisture and temperature. Proper curing can maintain a satisfactory moisture content and temperature in mortar and concrete during their early stages so that the desired properties may develop $[21,22]$. The necessity for curing arises from the fact that the hydration of cement can only take place in water-filled capillaries. Therefore, in order to obtain good mortar and concrete, the placing of an appropriate mix must be followed by curing in a suitable environment during the early stages of hardening and the loss of water by evaporation from capillaries must be prevented [23, 24]. Curing is used to provide an appropriate environmental condition within a concrete structure (relative humidity and temperature) to ensure the progress of the hydration reaction, which causes the filling and segmentation of capillary voids by hydrated compounds. In a specific condition, to achieve an adequate hydration of Portland cement mortars and concretes the curing duration mainly depends on the chemical and mineralogical compositions, and also the fineness of the cement. ACI 308 recommended practice [25] suggests 7 days of moist curing for most structural concretes. However, the period of curing should be extended to 14 days when the cement contains supplementary cementitious materials, such as slag and fly ash, owing to the slow hydration reactions between supplementary cementitious materials and the calcium hydroxide $(\mathrm{CH})$. The process of this reaction requires the presence of water to produce the cementing compounds to contribute to filling the capillary voids.

According to Powers T. C. [26], a minimum of $80 \%$ humidity is required for the hydration of cement. Moreover, he suggested that the permeability of the surface concrete may increase five to ten fold if the concrete is insufficiently cured. The most effective method of curing is to keep the exposed concrete surface continuously moist by ponding and spraying with water. In this method, the concrete is kept fully saturated during the period, the ideal condition for strength development and hydration of cement. If the potential of mortar and concrete concerning strength and durability is to be fully realized, it is most essential that they be adequately cured. The curing becomes even more important if they contain supplementary cementious materials such as ground granulated blast furnace slag, fly ash, or silica fume and are subjected to dry and hot environments immediately after casting [27]. As shown in Table 4, the OPC-slag mortars cured in air under room temperature have less and higher strengths compared to OPC mortars and slag mortars, respectively at all ages.

It is noted that there is a notable difference between the strengths for both curing regimes. It can be said that the highest strengths are attributed to OPC mortars and the lowest to slag mortars for the air curing regime. This is true at all ages. This shows that both the slag mortars and OPC-slag mortars have high sensitivity to the curing regime. It is clear that the OPC-slag mortars cured in the water have less and higher strengths compared to the OPC mortars and slag mortars at early ages, respectively, i.e., 1, 3, and 7 days. However, it was observed that they have a remarkable increase in the strengths at later ages compared to both OPC mortars and slag mortars at the same ages. Generally, it can be said that the slag mortars have the lowest strengths at all ages compared to both OPC mortars and OPC-slag mortars. This is because the slag is a latent potential material that cannot have strength improvement at early ages, moreover, the slag is not 
able to increase strength compared to OPC because the hydration heat of OPC is more than that of the slag for the same content.

As given in Table 5, it is clear that increasing the rate of strength at 3 days compared to 1 day, i.e. i3/1 for the three groups of mortars when they are cured in air under room temperature is more than that when cured in the water; e.g., i3/1 for OPC mortar is 1.54 and 1.32 for air and water curing regimes, respectively. For duration of 3 to 7 days, this is only true for OPC mortars and it is reversed for both slag mortars and OPC-slag mortars for durations of 3 to 90 days. It seems that this is due to the slag mortars and OPC-slag mortars including slag. This is because the slag is a pozzolanic material, which can achieve the highest reaction with water at later ages.

The highest increasing rate of strength for all three groups of mortars in both curing regimes, air and water, was obtained for duration of 1 to 3 days. For durations of 3 to 7 days, the increasing rate of strength for both curing regimes was slow compared to the duration of 1 to 3 days. For all three groups of mortars cured in air under room temperature, the increasing rate of strength was reduced for durations of 7 to 28 days compared to durations of 3 to 7 days, however, in contrast it was seen that the strengths were increased for OPC mortars and OPC-slag mortars when they were cured in water. However, there was a reduction in strength for the slag mortars when they were cured in the water. For durations of 28 to 56 days there was a reduction in strength for all the mortars for curing regimes, air and water. Moreover, the slag mortars and OPC-slag mortars had a strength loss at 56 days compared to 28 days when cured in air under room temperature. For all three groups of mortars, variations in the compressive strength vs. age of curing are shown in Fig. 7 for curing regimes, water and air at room temperature, up to 90 days.

Table 4 Relative compressive strength of OMs, OSMs/50, and SMs.

\begin{tabular}{|c|c|c|c|c|c|c|}
\hline \multicolumn{7}{|c|}{ water curing } \\
\hline & 1 day & 3 days & 7 days & 28 days & 56 days & 90 days \\
\hline OM & 1.00 & 1.00 & 1.00 & 1.00 & 1.00 & 1.00 \\
\hline OSM/50 & 0.53 & 0.95 & 1.00 & 1.11 & 0.33 & 0.34 \\
\hline SM & 0.14 & 0.19 & 0.23 & 0.26 & 1.12 \\
\hline OM & 1.00 & 1.00 & 1.00 & 1.00 & 0.70 & 1.00 \\
\hline OSM/50 & 0.47 & 0.74 & 0.74 & 0.76 & 0.75 & 0.86 \\
\hline SM & 0.18 & 0.24 & 0.26 & 0.30 & 0.27 & 0.30 \\
\hline
\end{tabular}

Notes: $\mathrm{OM}=\mathrm{OPC}$ mortar, OSM/50 = OPC-slag mortar for 50\% replacement with slag, $\mathrm{SM}=$ slag mortar.

Table 5 Relative compressive strengths (i) for all the three groups of mortars.

\begin{tabular}{|r|c|c|c|c|c|}
\hline \multicolumn{1}{|c|}{ Mix name } & $\mathrm{i}_{3 / 1}$ & $\mathrm{i}_{7 / 3}$ & $\mathrm{i}_{28 / 7}$ & $\mathrm{i}_{56 / 28}$ & $\mathrm{i}_{90 / 56}$ \\
\hline OM- ac & 1.54 & 1.13 & 1.05 & 1.00 & 0.93 \\
\hline OM- wc & 1.32 & 1.09 & 1.19 & 1.01 & 1.11 \\
\hline OSM/50- ac & 2.44 & 1.13 & 1.07 & 0.99 & 1.07 \\
\hline OSM/50- wc & 2.37 & 1.14 & 1.32 & 1.02 & 1.12 \\
\hline SM- ac & 2.10 & 1.22 & 1.19 & 0.92 & 1.01 \\
\hline SM- wc & 1.71 & 1.34 & 1.31 & 1.31 & 1.12 \\
\hline \multicolumn{7}{|c|}{$\mathrm{i}$ is relative compressive strength and defined as: $\mathrm{i}=\mathrm{f}_{(\mathrm{t}+1)} / \mathrm{f}_{\mathrm{t}}$} \\
\hline
\end{tabular}

Notes: OSM $/ 50=$ OPC-slag mortars for 50\% replacement with slag, $\mathrm{OM}=\mathrm{OPC}$ mortar, $\mathrm{SM}=$ slag mortar, wc $=$ water curing, ac $=$ curing in air under room temperature. 

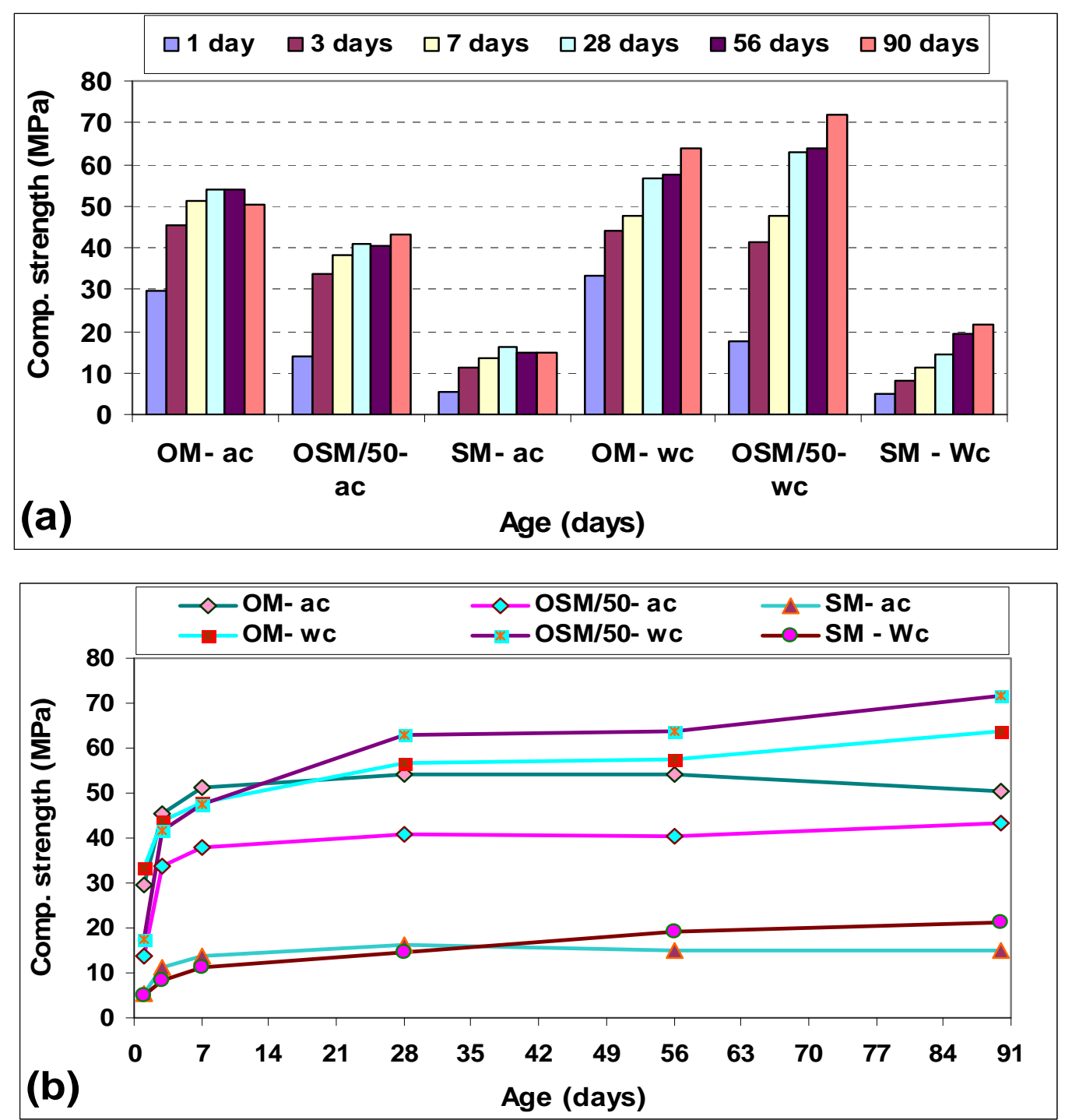

Fig. 7 Variations of compressive strength versus age of curing for the three groups of mortars cured in water and air under room temperature. (Notes: OSM/50 = OPC-slag mortar for 50\% replacement with slag, OM= OPC mortar, $\mathrm{SM}=$ slag mortar, wc $=$ water curing, ac = curing in air under room temperature.)

\subsection{Strength Loss and Affecting Factors}

From Fig. 8 (a) it is seen that there is no strength loss at early ages for all the three mortars - OPC-slag, OPC, and slag. This is true for all three groups of mortars when they are cured in either air or water at room temperature. From Fig.8 (b) it is observed that there is a strength loss for all three groups of mortars at later ages when they are cured in air. The strength loss was obtained for OPC mortars, OPC-slag mortars (for 50\% replacement with slag), and slag mortars at 90, 56, and 56 days, respectively. It should be noted that there is no strength loss for the mortars at later ages when they cured in the water. Once again, this shows the significant effect of the curing regime on the loss of strength. It is noted that based on the results previously obtained by the authors [10], strength loss was observed for the mortar specimens for $40 \%$ replacement with slag, although the specimens were cured in the water. The highest strength loss was seen in this mortar; this shows that the replacement level of slag instead of cement has a noticeable influence on strength loss. 

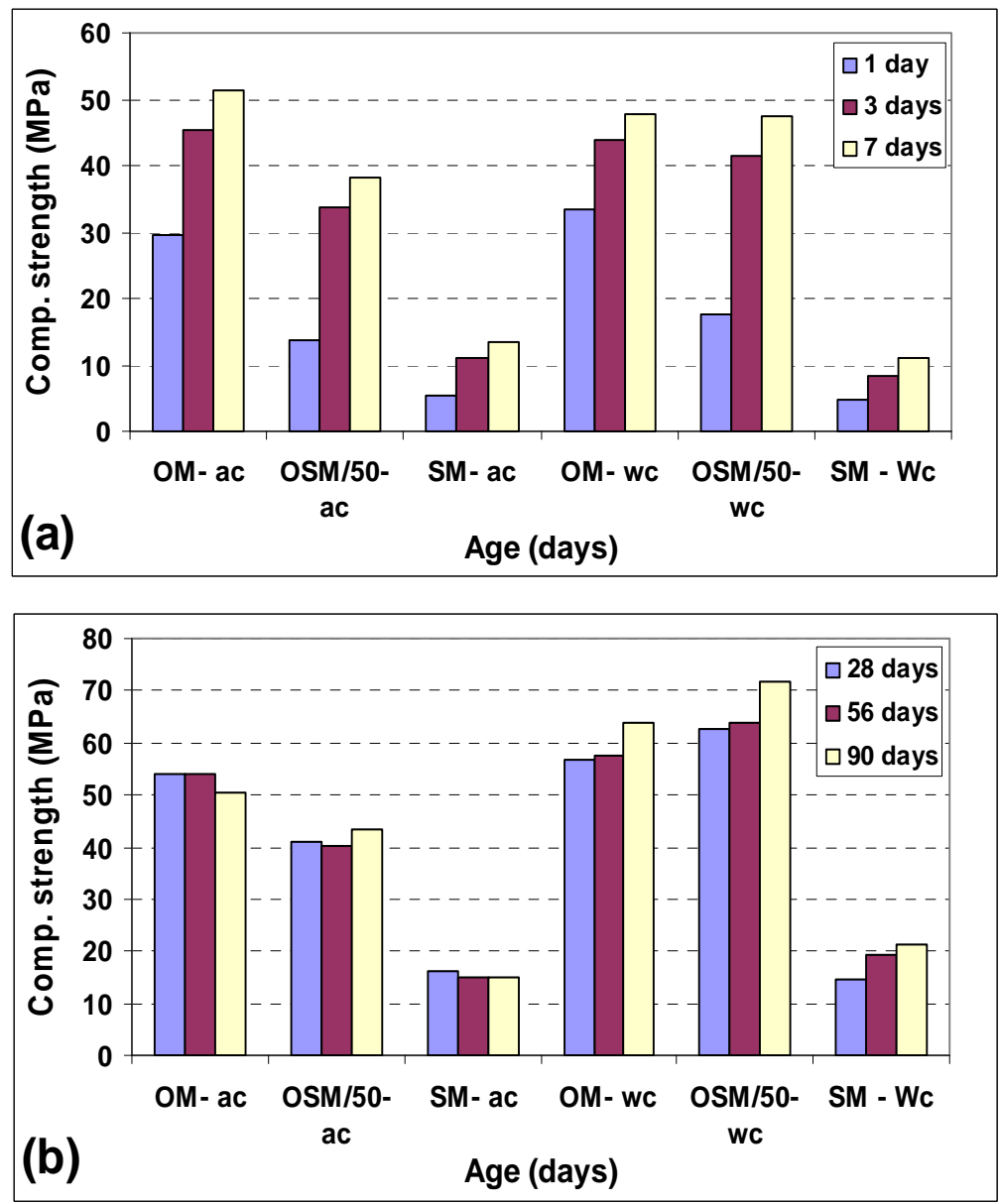

Fig. 8 Compressive strength loss for all the three groups of mortars (a)- at early ages, (b)- at later ages. (Notes: OSM/50= $\mathrm{OPC}$-slag mortar for 50\% replacement with slag, $\mathrm{OM}=\mathrm{OPC}$ mortar, $\mathrm{SM}=$ slag mortar, $\mathrm{wc}=$ water curing, ac $=$ curing in air under room temperature.)

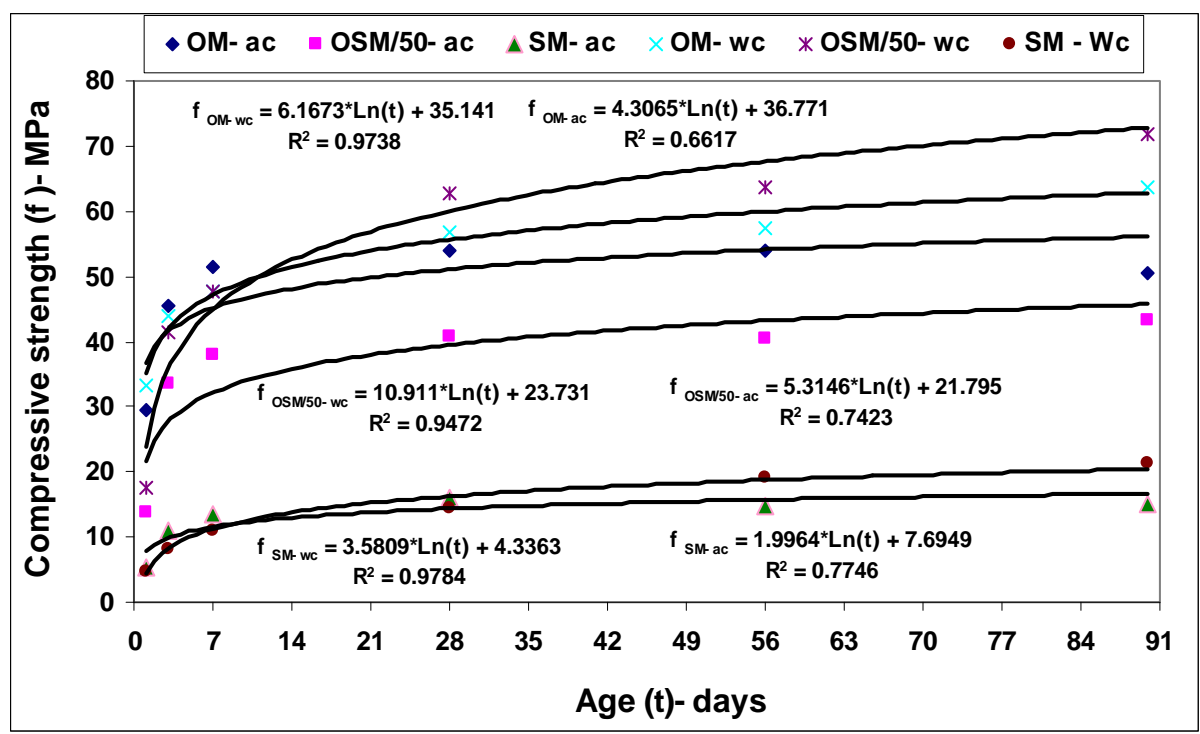

Fig. 9 Strength development curve fitting of OPC-slag mortars in water and air curing regimes. (Notes: OSM/50= OPC-slag mortar for $50 \%$ replacement with slag, $\mathrm{OM}=\mathrm{OPC}$ mortar, $\mathrm{SM}=$ slag mortar, wc $=$ water curing, ac $=$ curing in air under room temperature, $\mathrm{f}=$ compressive strength in $\mathrm{MPa}, \mathrm{R}^{2}=$ coefficient of determination.) 
From Table 5 it is seen that all three groups of mortars have strength loss at some later ages. Comparison of the strength loss coefficients for slag mortars, OPC mortars, and OPC-slag mortars as 0.92, 0.93 , and 0.99 , respectively, indicates that whenever curing is done in air under room temperature both OPC and slag should be used in the mortars, because of the strength loss coefficient for OPC-slag mortars, which is the lowest. It should be noted that using the optimum level of slag is recommended [10]. For durations of 56 to 90 days among the mortars cured in air it was observed that there was only a strength loss for OPC mortars and no strength loss for slag mortars and OPC-slag mortars. For this duration it is seen that there is approximately the same increasing rate of strength loss, 1.12, for all the mortars when they are cured in water. The compressive strength loss of mortars and concretes is a fact. In the process of this research, strength loss was observed for some of the mortars prepared. This is because of various reasons such as internal or external factors. The internal factors are those linked to the chemical composition of the reacted products. The most significant external factors are due to the variability of specimens and testing procedures. Another factor having high importance is the effect of temperature. The initial curing temperature has a significant effect and can reduce or increase strength at later ages. It seems that the main reason for strength loss at later ages is due to the lack of internal water in the specimens to complete the hydration process progression. Usually for the duration of 1 to 28 days, the internal water due to the water-binder ratio is available and adequate for the hydration process, however, beyond 28 days it is reduced and then insufficient for the process of hydration progress, furthermore, strength loss occurs.

\subsection{Strength Development Curve Fitting}

Whenever it is desired to know the behavior of a phenomenon, it is usual to model it using a diagram or mathematical equation. By using the proper relationship, the behavior of the phenomenon in the future can be approximately forecasted. In this study, based on the results obtained for all three groups of OPC-slag mortars the mathematical relationships have been determined to forecast the variations of compressive strengths vs. age of specimens. Based on the relationships obtained for strength development curve fitting it is observed that OPC-slag mortars have higher correlation coefficients, i.e., $\mathrm{R}^{2}$, when they are cured in water compared to curing in air at room temperature, e.g., for OPC-slag mortars for 50\% replacement with slag (OSM/50) cured in air and water the R2 obtained was 0.7423 and 0.9472 , respectively. This is also true for both OPC mortars and slag mortars. This shows that OPC-slag mortars are very sensitive to curing regimes and they have continuous strength development when they are cured in water. The results prove that the best curve fitting for strength development for all three groups of mortars is a logarithmic equation: $\mathrm{f}_{\mathrm{i}}=a^{*} \operatorname{Ln}(\mathrm{t})+b$; where $\mathrm{f}_{\mathrm{i}}$ is compressive strength at $i$ days in $\mathrm{MPa}$, $t$ is age of curing in days and $a \& b$ are the constant coefficients for each specified mortar. Strength development curve fittings are shown in Fig. 9. It is noted that among all of the given equations, the relationship of OPC mortar cured in air under room temperature has the least $\mathrm{R}^{2}$; this is because of the high sensitivity of OPC to the curing regime.

\section{Conclusions}

Based on the results obtained in this experimental work, the following conclusions can be drawn:

(1) The highest strengths were obtained at 90 days for the three groups namely OPC-slag mortars, OPC mortars, and slag mortars - cured in water, which were found to be 72, 64, and 21.5 MPa, respectively.

(2) It was observed that the highest strength growth for the three mortar groups mentioned above occurred in air at room temperature curing for duration of 1 to 3 days. The values of strength growth obtained for OPC-slag mortars, slag mortars, and OPC mortars are 
2.44, 2.10, and 1.54 for air curing regimes and 2.37, 1.71 , and 1.32 for water cured, respectively.

(3) It was revealed that all the three groups of mortars are sensitive to the curing regime, with the highest sensitivity for the slag mortars.

(4) It was proved that all the three groups of mortars had strength loss when they were cured in air under room temperature. The highest and lowest strength losses were $8 \%$ and $1.3 \%$, respectively.

(5) The maximum and minimum strength loss obtained was attributed to slag mortars and OPC-slag mortars at 56 and 90 days, respectively. However, it should be noted that none of the mortar groups had strength loss at early ages when they were cured in air and water.

(6) It was revealed that the level of replacement slag and curing regime are the factors with the highest significance concerning strength loss.

(7) Based on the results obtained for compressive strengths of the three groups of mortars cured in the both curing regimes air and water, it was obtained that the best strength development curve fitting for the mortars is a logarithmic equation as $\mathrm{f}_{\mathrm{i}}=a^{*} \operatorname{Ln}(\mathrm{t})+b$; where $f_{i}$ is compressive strength at $i$ days in MPa, $t$ is age of curing in days, and the factors $a$ and $b$ are constant coefficients for each specific mortar.

\section{References}

[1] F. Sajedi, Influence of activation methods on strength of ordinary Portland cement-slag mortars, 2011, University of Malaya, Kuala Lumpur, Malaysia.

[2] K. Sisomphon, O. Copuroglu and A. L. A. Fraaij, Durability of blast-furnace slag mortars subjected to sodium onofluorophosphate application, Constr Build Mater 2010, in Press.

[3] S. D. Wang, X. C. Pu, K. L. Scrivener and P. L. Pratt, Alkali-activated slag cement and concrete: A review of properties and problems, Adv Cem Res 27 (1995) 93-102.

[4] V. D. Glukhovsky, Soil silicates, Gosstroiizdat Publish, Kiev, Ukraine, 1959 (in Russian).

[5] S. D. Wang, K. L. Scrivener and P. L. Pratt, Factors affecting the strength of alkali-activated slag, Cem Concr Res 24 (6) (1994) 1033-1043.
[6] D. Hardjito, S. E. Wallah, D. M. J. Sumajouw and B. V. Rangan, On the development of fly ash-based geopolymer concrete, ACI Mater J 101 (6) (2004) 467-472.

[7] Keun-Hyeok Yang, Jin-Kyu Song, Ashraf F. Ashour and Eun-Taik Lee, Properties of cementless mortars activated by sodium silicate, Constr Build Mater 22 (8) (2008) 1981-1989.

[8] C. Shi, P. V. Krivenko and D. Roy, Alkali-Activated Cements and Concretes, Taylor and Francis, USA, 2006.

[9] Keun-Hyeok Yang, Jae-Il Sim and Sang-Ho Nam, Enhancement of reactivity of calcium hydroxide-activated slag mortars by the addition of barium hydroxide, Constr Build Mater 24 (3) (2010) 241-251.

[10] F. Sajedi and P. Shafigh, Optimum Level of Replacement Slag in OPC-Slag Mortars, J Civ Eng Archit 4 (1) (2010) $11-19$.

[11] Wei Chen, Hydration of slag cement: Theory, Modeling, and Application, $\mathrm{PhD}$ Thesis, the University of Twente, Netherlands, 2007.

[12] Md. Moinul Islam et al., Strength behavior of mortar using slag with cement in sea water environment, J Civ Eng- IEB 37 (2) (2009) 111-122.

[13] S. C. Pal, A. Mukherjee and S. R. Pathak, Investigation of hydraulic activity of ground granulated blast furnace slag in concrete, Cem Concr Res 33 (9) (2003) 1481-1486.

[14] ASTM C109/C109M- 08 Standard Test Method for Compressive Strength of Hydraulic Cement Mortars (Using 2-in. or [50-mm] Cube Specimens).

[15] ASTM C989- 09a Standard Specification for Slag Cement for Use in Concrete and Mortars.

[16] A. M. Neville, Properties of Concrete, Prentice Hall, Malaysia, 2008.

[17] A. M. Neville and J. J. Brooks, Concrete Technology, Prentice Hall, Malaysia, 2008.

[18] ASTM C494/C494M- 10 Standard Specifications for Chemical Admixtures for Concrete.

[19] United States Bureau of Reclamation, 1849 C Street NW, Washington DC 20240- 0001.

[20] ASTM C230/C230M- 08 Standard Specifications for Flow Table for Use in Tests of Hydraulic Cement.

[21] X. Sharon Huo, Ling Ung Wong, Experimental study of early-age behavior of high performance concrete deck slabs under different curing methods, Constr Build Mater 20 (10) (2006) 1049-1056.

[22] E. G. Nawy, Concrete construction engineering handbook, Boca Raton (NY): CRS Press, 1997, pp. 20-55.

[23] M. Oner, K. Erdogdu and A. Gunlu, Effect of components fineness on strength of blast furnace slag cement, Cem Concr Res 33 (4) (2003) 463-469. 
[24] Y. M. Zhang and T. J. Napier-Munn, Effects of particle size distribution, surface area and chemical composition on Portland cement strength, Powder Technol 83 (3) (1995) 245-252.

[25] ACI Committee 308, Recommended Practice for Curing Concrete, MCP, American Concrete Institute, Farmington Hills, USA, 1998.
[26] T. C. Powers, A discussion of cement hydration in relation to the curing of concrete, Proc Highway Res Board 27 (1947) 178-188.

[27] E. C. Higginson, The effect of cement fineness on concrete: Fineness of cement; ASTM STP 73, 1970. 